resistance which increases after loss of the placental circuit at birth. Intrauterine congestive heart failure with gross oedema at birth and supraventricular tachycardia has however been described. ${ }^{7}$ Likewise hydropic appearances at birth associated with congenital heart block have only rarely been described, ${ }^{5}$ congestive failure usually occurring after birth and being attributed to alterations in systemic vascular resistance.

In the siblings described, it is reasonable to assume that the aetiology of the congenital heart block was similar. Echocardiographic examination of both infants was normal. Both had normal Hb levels with no evidence of haemolysis, and their mother at no time had any evidence of a connective tissue disorder.

Rhythm disorders in the fetus, whether tachycardia or bradycardia, are rarely associated with hydrops fetalis, even when of several months' duration. In the infants described, only one developed hydrops, this one being the least severely affected in terms of bradycardia. It is suggested that the gross oedema seen in the second infant at birth was a disorder of serum osmolality occurring secondarily to the disease process which produced the familial congenital heart block, rather than the direct result of congestive cardiac failure in the fetus.

\section{References}

1 Morquio L. Sur une maladie infantile et familiale characterisée par des modifications permanentes du pouls, des attaques syncopales et epileptiformes et la mort subite. Arch Med Enfants 1901 ; 4: 467-75.

2 Michaelsson M, Engle M A. Congenital complete heart block. An international study of the natural history. Cardiovasc Clin 1972; 4: 85-101.

3 Lev M, Caudros H, Paul M H. Interruption of the atrioventricular bundle with congenital atrioventricular block. Circulation 1971 ; 43: 703-10.

4 Lev M. Pathogenesis of congenital atrioventricular block. Prog Cardiovasc Dis 1972; 15: 145-57.

5 Hardy J D, Solomon S, Banwell G S, Beach R, Wright V, Howard F M. Congenital complete heart block in the newborn associated with maternal systemic lupus erythematosus and other connective tissue disorders. Arch Dis Child 1979; 54: 7-13.

- Ferrer P L. Arrhythmias in the neonate. In: Roberts N K, Gelband $\mathrm{H}$, eds. Cardiac arrhythmias in the neonate, infant, and child. New York: Appleton-Century-Crofts, 1977.

7 Silber D L, Durnin R E. Intrauterine atrial tachycardia associated with massive edema in a newborn. Am $J$ Dis Child 1969; 117: 772-6.

8 Altenburger K M, Jedziniak M, Roper W L, Hernandez I. Congenital complete heart block associated with hydrops fetalis. J Pediatr $1977 ; 91$ : 618-20.

Correspondence to Dr R W I Cooke, Institute of Child Health, Alder Hey Children's Hospital, Eaton Road, Liverpool 12 2AP.

\title{
Effect of parental head circumference on that of the newborn child
}

\author{
JOHN OSBORNE, S HAVALAD, B HUDSON, AND A HUGHES \\ Department of Paediatrics, Southmead Hospital, and Department of Community Health, Bristol
}

SUMMARY The head circumferences of 74 term, normal babies were measured, together with the head circumferences of their parents. Maternal head circumference had a significant effect on that of the newborn infant but paternal head circumference had not. An equation is given for estimating the expected head circumference of a newborn infant, provided the birthweight and maternal head circumference are known.

The effects of gender and gestational age on head circumference in infancy have been studied, and charts have been produced allowing for these variations. ${ }^{1}$ Head circumference can also be affected by birthweight, severe intrauterine growth retardation, or congenital abnormality. ${ }^{2}$ Head shape influences head circumference as does moulding for the first 36 hours of life. ${ }^{3}$ It has been suggested that parental head size can account for some of the variation in head size of babies. ${ }^{4}$ In this study this possibility was examined.

\section{Subjects and methods}

74 newborn infants and their parents were studied. Each baby was weighed at birth on two separate scales by two different pairs of nurses to avoid errors. Head circumference was measured by two of us ( $\mathrm{J} \mathrm{O}$ and S H) between 48 and 120 hours of life when the effect of moulding had disappeared. ${ }^{3}$ Gestational age was assessed from the date of the mother's last menstrual period as given at booking. The parents' head circumferences were measured by one of us $(\mathrm{B} \mathrm{H})$ with a fibreglass tape. Disposable paper tapes were used for the babies. The accuracy 
of all the tapes was checked against a wooden rule. The head circumference measured was between the glabella and the occipital protruberance (the occipito-frontal circumference). The three of us practised these measurements for several weeks until similar and consistent results were obtained. The mother's height was measured at booking.

Babies were excluded from the study for the following reasons: (1) Gestational age more than 42 or less than 37 complete weeks by dates. (2) Birthweight less than $2.5 \mathrm{~kg}$. (3) Diabetes mellitus or abnormal postnatal glucose tolerance in the mother measured when the birthweight was more than 4 kg. (4) Congenital abnormality. (5) Cephalhaematoma. (6) Nonwhite race. (7) Mother unmarried at booking. (8) Discharge less than 5 days after delivery.

The results were analysed using stepwise multiple regression techniques with the 4 independent variables of birthweight, gestational age, maternal head circumference, and paternal head circumference. The baby's head circumference was the dependent variable. In order to combine data from both sexes, $0.6 \mathrm{~cm}$ was added to each female baby's head circumference and this was called the adjusted head circumference.

\section{Results}

The mean head circumference of the 41 male babies was $35 \cdot 2$ (SD 1.28) cm while that of the 33 female babies was $34 \cdot 6$ (SD 1.11) $\mathrm{cm}$. The difference $(0.6 \mathrm{~cm})$ was significant $(P<0.05)$ and was identical with that found in larger series. ${ }^{5}$

Initial analysis was undertaken for both sexes combined. Birthweight was the most significant independent variable $(r=0.74)$ explaining $53.7 \%$ of the variation in head circumference. Maternal head circumference was also a significant independent variable $(r=0 \cdot 36)$ although it explained only an additional $4.1 \%$ of the variation. Gestational age and paternal head circumference were not significant independent variables. The regression equation relating baby's head circumference to birthweight and maternal head circumference was

Baby's adjusted $\mathrm{HC}=18 \cdot 9+(1.93 \times \mathrm{BW})+(0 \cdot 18$ $\times$ maternal HC)

where $\mathrm{HC}=$ head circumference (in $\mathrm{cm}$ ), $\mathrm{BW}=$ birthweight (in $\mathrm{kg}$ ). Adjusted $\mathrm{HC}=$ true $\mathrm{HC}$ for males, but is $0.6 \mathrm{~cm}$ larger than the true $\mathrm{HC}$ for females.

At the mean of each independent variable the constant term contributed $53.6 \%$ of the head circumference, birthweight contributed $18.6 \%$, and maternal head circumference contributed $27 \cdot 8 \%$.

If each sex is considered separately birthweight remains the most significant independent variable (for the males $r=0.76$ explaining $57.9 \%$ of the variation: for the females $\mathrm{r}=\mathbf{0 . 7 0}$ explaining $48.4 \%$ of the variation), but for males alone the maternal head circumference is a second significant independent variable explaining a further $8.5 \%$ of the variation.

\section{Discussion}

Birthweight had a greater influence on head circumference than had been noted previously. ${ }^{2}$ This was probably because infants of diabetic mothers and small-for-dates babies were excluded. Our data are comparable with the increase in head circumference seen due to increasing gestational age, and hence to increasing weight, in term babies. ${ }^{1}$

The lack of effect of gestational age was probably due to the restricted range of this variable in the babies. It was not accounted for by birthweight as if birthweight were to be excluded as an independent variable, gestational age would still not be a significant factor. The relative inaccuracy of measuring gestational age by dates alone may be a contributory factor but attempts to replace it, or even complement it, by data based on Dubowitz scores showed no additional benefit.

In an attempt to understand the lack of significance of maternal head circumference in the female babies further analyses were undertaken. In the general population there is a correlation between maternal height and maternal head circumference $(r=0 \cdot 3)$ (J M Tanner, 1979, personal communication) and between maternal height and birthweight $(\mathrm{r}=0 \cdot 25)^{6}$ and this was true for our survey when both sexes were combined $(r=0.3$ and $r=0 \cdot 3)$. However, for the males there was no significant correlation between maternal height and maternal head circumference, while for the females there was no significant correlation between maternal height and birthweight. This suggested that our sample was too small to analyse the sexes separately.

The regression equation can be used to predict a baby's head circumference if birthweight and maternal head circumference are known. The standard error of the residuals is $0.79 \mathrm{~cm}$, indicating that observations outside $\pm 1.55 \mathrm{~cm}$ of that predicted might be considered abnormal and require further clinical investigation. This was tested on 2 patients who each had had a very small head at birth which had initially been thought to be due to significant microcephaly. Subsequent observations suggested it was due to the familial occurrence of microcephaly in otherwise normal children and their normal parents. However, the actual head circumferences were $2 \cdot 2$ and $2 \cdot 7 \mathrm{~cm}$ below the calculated head circumferences, suggesting that a wider margin of 
normality is required. This problem of predicting the deviation expected in theanthropometric measurements of unusual individuals by studying the variation in normal individuals has already been recognised with regard to height. ${ }^{\text {? }}$

\section{References}

1 Gairdner D, Pearson J. A growth chart for premature and other infants. Arch Dis Child 1971; 46: 783-7.

2 Illingworth R S, Lutz W. Head circumference of infants related to body weight. Arch Dis Child 1965; 40: 672-6.

3 Baum J D, Searls D. Head shape and size of newborn infants. Dev Med Child Neurol 1971; 13: 572-5.
4 Illingworth R S. The development of the infant and young child. 5th ed. Edinburgh: Churchill Livingstone, 1972: 135.

5 Nelson W E. Textbook of pediatrics. 8th ed. Philadelphia: Saunders, 1964: 48 .

6 Tanner J M, Thomson A M. Standards for birthweight at gestation periods from 32 to 42 weeks, allowing for maternal height and weight. Arch Dis Child 1970; 45: 566-9.

7 Tanner J M, Goldstein H, Whitehouse R H. Standards for children's height at ages 2-9 years allowing for height of parents. Arch Dis Child 1970; 45: 755-62.

Correspondence to Dr J Osborne, Bristol Royal Hospital for Sick Children, St Michael's Hill, Bristol BS2 8BJ.

\section{$\alpha$-Thalassaemia and hyperbilirubinaemia in G-6-PD-deficient newborns}

\section{TULLIO MELONI, RACHELE CORTI, SINFAROSA COSTA, GRAZIELLA MELE, AND VANNINA FRANCA}

Children's University Hospital, Sassari, Italy

\begin{abstract}
SUMMARY 53 newborn infants with both G-6-PD deficiency (29 male hemizygotes and 24 female heterozygotes) and $\alpha$-thalassaemia, and 120 newborn infants with only the enzymatic defect (60 male hemizygotes and 60 female heterozygotes) were stud:ed. 12 of those with both G-6-PD deficiency and $\alpha$-thalassaemia, and 32 of those with only G-6-PD deficiency showed hyperbilirubinaemia. $\alpha$ Thalassaemia does not seem to be implicated in the development of hyperbilirubinaemia in G-6-PDdeficient newborns.
\end{abstract}

It is known that erythrocyte G-6-PD deficiency, predisposes to the risk of severe neonatal hyperbilirubinaemia. However, the frequency of this association varies in different populations and in different regions. ${ }^{1-4}$ Therefore, additional genetic or environmental factors, or both, must play a part. $\alpha$-Thalassaemia has been suspected as being one of the genetic factors because neonatal jaundice associated with G-6-PD deficiency is common in the Chinese, ${ }^{5}$ in whom $\alpha$-thalassaemia is also common.

This study was designed to confirm or refute the association of $\alpha$-thalassaemia and neonatal hyperbilirubinaemia in G-6-PD-deficient newborn infants.

\section{Materials and methods}

10160 term infants (5468 girls, 5692 boys) born at the University of Sassari, Department of Obstetrics and Gynaecology, during a 5-year period (from 1973 to 1978) were screened for G-6-PD deficiency and $\alpha$-thalassaemia. Of these 10160 infants studied, 262 girls and 271 boys were found to be $\alpha$-thalassaemic; 441 boys and 514 girls (467 heterozygotes and 47 homozygotes) were G-6-PD deficient. 53 term newborn infants weighing between $3 \cdot 1$ and $3 \cdot 8$ $\mathrm{kg}$ were G-6-PD-deficient (29 male hemizygotes, 24 female heterozygotes) and $\alpha$-thalassaemic. None of the 53 infants was given phenobarbitone, orotic acid, or agar prophylaxis and none had blood group incompatibilities, hypoglycaemia, respiratory distress, infection, or cephalhaematoma. Those with bilirubin levels equal to, or higher than, $10 \mathrm{mg} / 100$ $\mathrm{ml}(171 \mu \mathrm{mol} / \mathrm{l})$ on the first day of life, $12 \mathrm{mg} / 100 \mathrm{ml}$ $(205 \mu \mathrm{mol} / \mathrm{l})$ on the second day, and $14 \mathrm{mg} / 100 \mathrm{ml}$ (239 $\mu \mathrm{mol} / \mathrm{l})$ on the third and following days were considered hyperbilirubinaemic and given phototherapy. 120 term newborn infants weighing between 3.0 and $3.9 \mathrm{~kg}$ with only G-6-PD deficiency (60 male hemizygotes and 60 female heterozygotes) served as controls.

Erythrocyte G-6-PD activity was assessed using the test of Brewer et al. ${ }^{6}$ In a girl with a positive result to the test a diagnosis of heterozygosity or homozygosity was made using the cytochemical method of Sansone et al. ${ }^{7}$ Diagnosis of $\alpha$ thalassaemia was made by demonstrating $\mathrm{Hb}$ Bart's electrophoretically on cellogel strips. Bilirubin determination was by the Malloy and Evelyn method. ${ }^{8}$

\section{Results}

Results are reported in the Table and Figure. 